\title{
Exploring Greek High School Students' Understanding of Basic Environmental Issues
}

\author{
Christos A. Tsekos ${ }^{1}$, Aikaterini Plakitsi ${ }^{2}$ Dimosthenis G. Theocharopoulos ${ }^{1}$, \\ Demetrios P. Matthopoulos ${ }^{1}$ \\ ${ }^{1}$ Department of Environmental and Natural Resources Management, School of Natural Resources and Enterprises Management, \\ University of Western Greece, Agrinio, Greece \\ ${ }^{2}$ Department of Early Childhood Education, School of Education, University of Ioannina, Ioannina, Greece \\ Email: ca.tsekos@yahoo.gr, kplakits@cc.uoi.gr, dtheoh@cc.uoi.gr,dmatthop@cc.uoi.gr
}

Received November 22, 2012; revised December 23, 2012; accepted January 1, 2013

\begin{abstract}
The present research studies the knowledge of 221 Ioannina's city, located in the northwestern region of Greece, high school students on 10 environmental issues. Schoolers' responses were collected through a "closed response" questionnaire distributed at three of the city's Public High Schools. The overall picture appeared to be moderately satisfactory, as high schoolers possess a good knowledge on several environmental issues, while misconceptions on other issues, such as sustainable development, predominate. Taking into account the outcome of the present study we consider that improvements are needed in the existing Environmental Education Program in order to ameliorate their knowledge.
\end{abstract}

Keywords: Children’s Ideas; Misconceptions; Environmental Issues; Constructivism; Environmental Education

\section{Introduction}

Pupils joining formal education system have already developed notions and intellectual experiences on both natural and anthropogenic environment. These notions, the so-called alternative ideas, preconceptions, spontaneous concepts and misconceptions [1-4] have been developed through various types of human socialization, such as family, school, mass media etc., in connection with the different meanings and phenomena.

Among the different learning theories, constructivism underlines pupils' stimulation by their teachers as far as alternative ideas are concerned. Constructivism's basic principle is that a pupil does not come to school as tabula rasa; on the contrary, knowledge is constructed based on someone's previous experiences [5,6]. Ausubel et al. [7] and Posner et al. [8] pointed out that according to Constructivism teachers should re-construct pupils' knowledge based on their initial ideas instead of ignoring them. The North American Association for Environmental Education recommends pupils' stimulation with regard to their alternative ideas through Environmental Education [9].

Although several studies were carried out in Greece in relation to primary, middle and high schoolers' ideas on individual environmental issues, such as air pollution, mountain regions and others [10-14], studies aiming to investigate pupils' knowledge on environmental issues as a whole are relatively limited. Such a study exploring the broader knowledge is the one of Kastani et al. [13]. Furthermore a new emerging paradigm is being addressed by Plakitsi et al. [14] concerning a holistic cultural historical approach in science and environmental education.

Taking into account that environmental issues are interdependent, an attempt on evaluating the total-general knowledge of schoolers on these issues appears to be useful.

\section{Methodology}

In the present study a closed response questionnaire with 10 questions was used. The contained questions are listed as an Annex at the end of the present article. Worth mentioning is that during the interviews at Schools, the schoolers were informed, by members of the research team and their school teachers', for the purposes of this survey, as well as that completing the questionnaire is anonymous and voluntary.

221 schoolers from three High Schools of the city of Ioannina in North western Greece participated in the study. The schools are public and operate in urban areas. 77 of the participated schoolers followed first-class (34.84\%), 73 followed second-class (33.03\%) and 71 followed third-class courses (32.13\%).

The analysis of the results was carried out with the 
Statistical Package for Social Sciences (SPSS) and the $\mathrm{x}^{2}$ (Chi-Square) test in order to assess the degree of correlation of two factors: a) the age of children (expressed through the class they followed) and b) their knowledge (expressed through their response to the 10 questions) ( $p$ $<0.05)$.

\section{Results and Discussion}

The first question aimed to explore whether students are aware the difference between the Waste Landfill and the abandoned waste sites. It is worth noting at this point that the construction of a Waste Landfill in Greece over the recent years has several times caused serious social tensions, which indicates that people are largely ignorant of the fact that a Waste Landfill is specially designed to protect the environment. Looking into pupils responses' over this very important issue, we observe that they largely answered correctly, selecting the second reply, with rates of $85.7 \%, 79.5 \%$, and $81.7 \%$ for (A), (B) and (C) class respectively (Figure 1(a)). The fact that most students seem to be aware that a waste landfill, in contrast to an abandoned waste site, is designed to protect the environment, we consider it very important since, in everyday life, there is a frequent confusion and a coidentity of these two concepts. A similar research that was carried out in high and secondary school students in Nigeria revealed minor knowledge to pupils for waste management methods that are friendly to the environment, such as recycling and composting. Interviewing students for which method of waste disposal they would like to implement in their school, most of them replied combustion and burring in landfill sites [15].

The second question of the questionnaire intended to inform us about students' knowledge and misconceptions on the key environmental issue of greenhouse effect.
Schoolers largely answered incorrectly selecting the second answer, that the greenhouse effect is related to the UV radiation penetrating the atmosphere. It received the highest rates, while the percentages of the correct answer that was the third one, were $14.3 \%, 13.7 \%$ and $26.8 \%$ for (A), (B), and (C) classes respectively (Figure 1(b)). The large percentage of incorrect answer does not seem to be particularly associated with the age of the pupils, while it is clear that the students confuse the mechanism created by a phenomenon with the effects of another one. Analogous results of serious misconceptions between the greenhouse effect and thinning of the ozone layer revealed a study among Chinese high school students [16] and in England [17], while the same was observed in an investigation in Turkey where approximately the $80 \%$ of students indicated that global warming will lead to an increase in skin cancer [18].

In the third question students were asked about the value of the $\mathrm{pH}$ of acid rain. Acid rain, as it is known, has a $\mathrm{pH}$ value of less than 5.6 , which is the $\mathrm{pH}$ value of normal rain. The correct answer was satisfactorily marked only by the (C) class schoolers (84.5\%), while the percentage of the correct answer by the (A) and (B) class schoolers was significantly reduced $(59.7 \%$ and $57.5 \%$ respectively) (Figure 2(a)). At the same time, we note that the percentage of the incorrect first answer of the two smaller classes (A) and (B) was quite high (27.3\% and $35.6 \%$ ), which to our opinion, was not to be expected, as that the acidic solutions have a $\mathrm{pH}$ value of less than 7 is one of the first things they learn in middle school, called in Greece Gymnasium.

The fourth question aimed to explore the ideas of schoolers on biodiversity, which decreases under the present conditions of Environmental Management. The majority of (A) and (C) class schoolers by selecting the

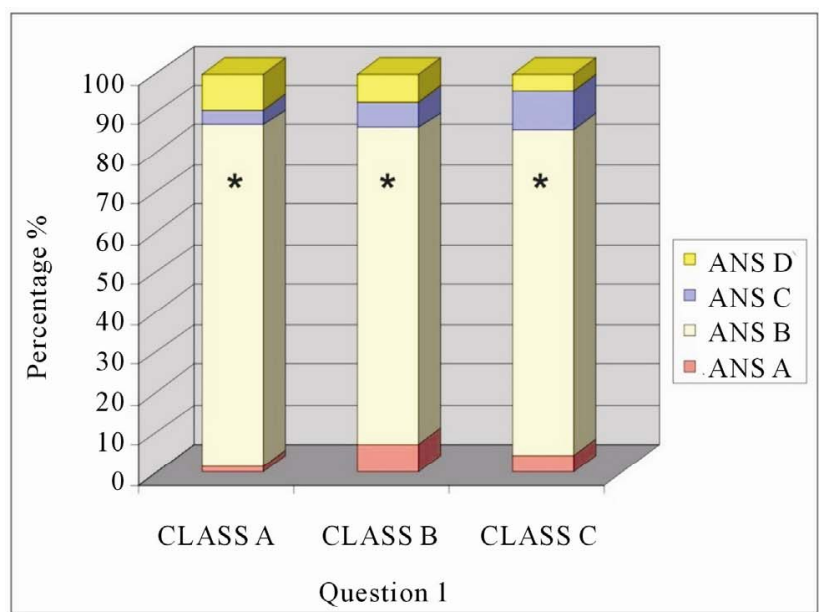

(a)

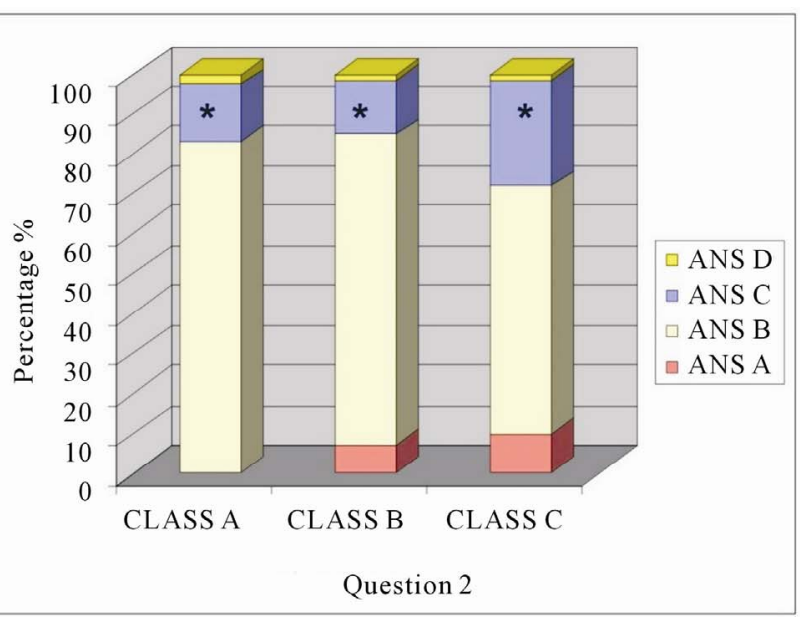

(b)

Figure 1. Percentage distribution of schoolers' responses to questions 1 and 2: (a) Question 1, (b) Question 2. *Denotes the correct option. 
second option answered correctly with response rates of $70.1 \%$ and $71.8 \%$ respectively, while almost half of the (B) class ones (56.16\%) responded correctly (Figure 2(b)), rates that should be considered relatively satisfactory. These results broadly agree with the results of an earlier research carried out in England and Mexico. That study revealed good knowledge and understanding of important concepts, such as endangered species or the extinction of a particular species [19]. However, an important factor that differentiates the knowledge of pupils in this particular issue seems to be their cultural background. In this survey, English schoolers possessed better knowledge than the Mexican ones, while it is worth mentioning that in another survey investigating the comprehension of biodiversity in schoolers with different cultural backgrounds (Chile and Germany), the Chileans ones presented a better knowledge on plant and animal species in comparison to the German ones [20].

The fifth question was designed to explore schoolers' knowledge on the key environmental issue of water cycle. It is well known that the water cycle is disturbed by the reduction of water quantities (e.g. due to intense droughts) and not from its contamination. Thus the correct answer is the second option. Schoolers' correct answers, regardless of their age, were relatively few, with the respective percentage rates (from (A) to (C) class) are respectively $39 \%, 34.2 \%$ and $26.8 \%$, while, as seen in Figure 3(a), their majority in all three classes chose the wrong first option. It is particularly important that, as it is clear from the above, schoolers seem to perceive that environmental pollution is responsible for all disorders in natural systems, regardless if this is not always the case. In previous studies as well, an incomplete knowledge of the hydrological cycle operation mechanism was observed $[12,21$, 22].

In the next question, schoolers were asked about the size of human population. The continuous increase of the world population, nowadays it reaches 6.5 billion, became a key environmental issue, as in the next 50 years will tend to reach the extremity of 9 billion. It is particularly important that their vast majority selected the correct option at a rate of approximately $80 \%$ in (A) and (B) and $90 \%$ in (C) class, as seen in Figure 3(b).

The seventh question was designed to explore their knowledge and misunderstandings on another important environmental issue, the thinning of the Ozone Layer. As seen in Figure 4(a), only (C) class schoolers responded correctly to the satisfactory rate of $73.2 \%$, while the percentage of (A) and (B) class ones that selected the correct option was $40.2 \%$ and $47.9 \%$ respectively, a fact that should be considered as being of moderate satisfaction. The number of schoolers that selected the correct third option is related to their age. Another important observation is that there is confusion on the concept of global warming and thinning of the ozone layer, as observed in the second question as well, since the wrong second option rated $38.9 \%$ and $27.4 \%$ for (A) and (B) class schoolers respectively. Other investigations carried out in England [17] and in the USA [23] also reported significant schoolers confusion over the notion of these two phenomena. Meanwhile, with regard to the knowledge of the ozone layer destruction mechanism, the data obtained in an earlier Greek schoolers' survey were characterized as unsatisfactory. The data indicated that although the majority of schoolers were aware of the ozone layer location and that it protects us from ultraviolet radiation, only the one third of them (31\%) were aware that the ozone-depleting chemicals are used in the refrigerators and are not part of the cloud resulting from cars and industry as erroneously stated approximately the $80 \%$ of them [24].

In the eighth question (about renewable energy) the

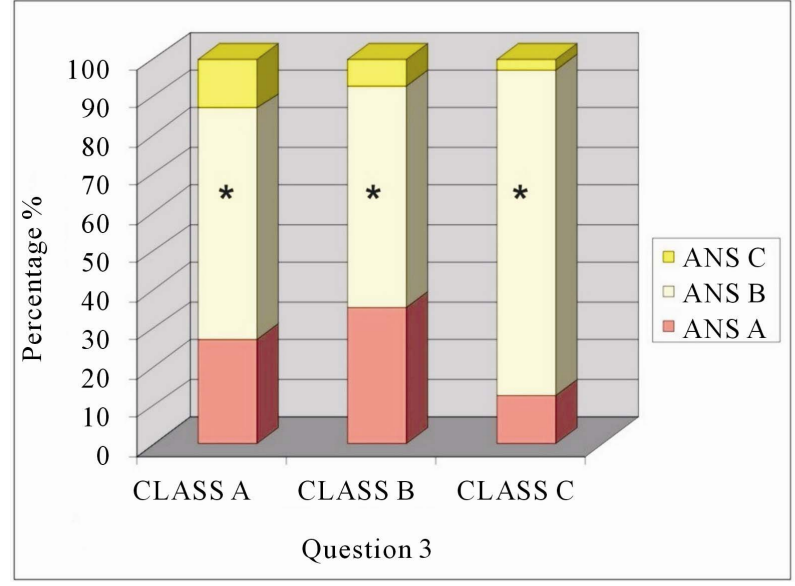

(a)

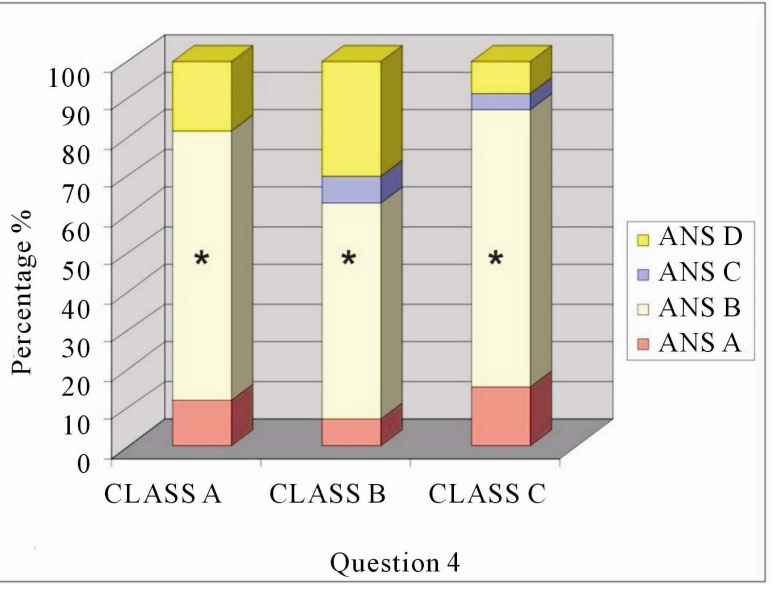

(b)

Figure 2. Percentage distribution of schoolers' responses to questions 3 and 4: (a) Question 3, (b) Question $4 .{ }^{*}$ Denotes the correct option. 


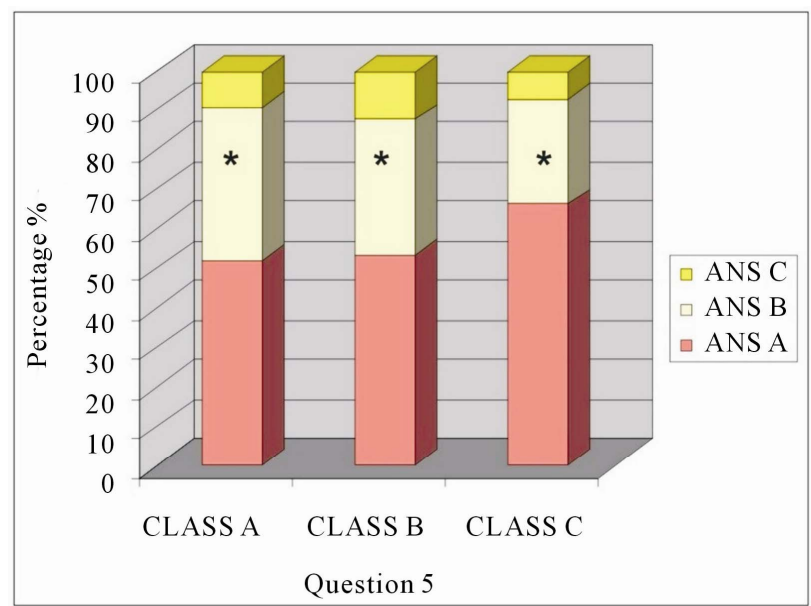

(a)

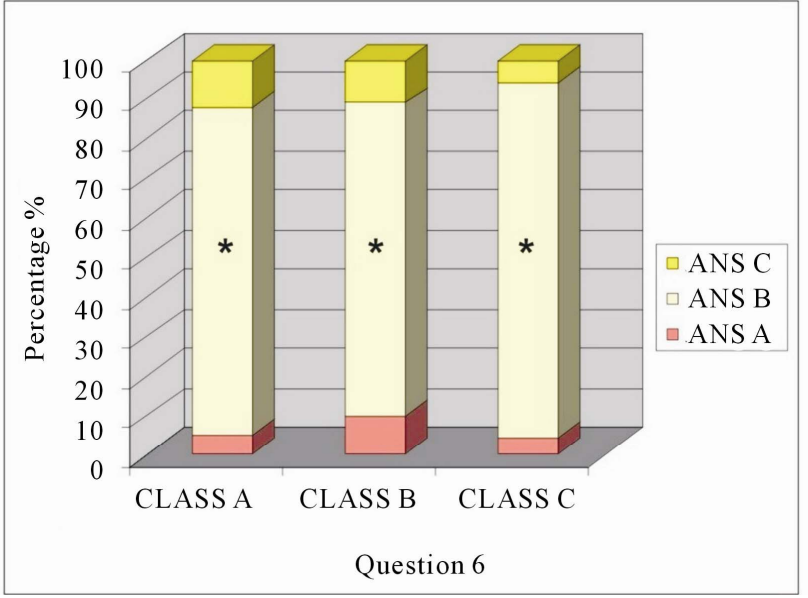

(b)

Figure 3. Percentage distribution of schoolers' responses to questions 5 and 6: (a) Question 5, (b) Question 6. 'Denotes the correct option.

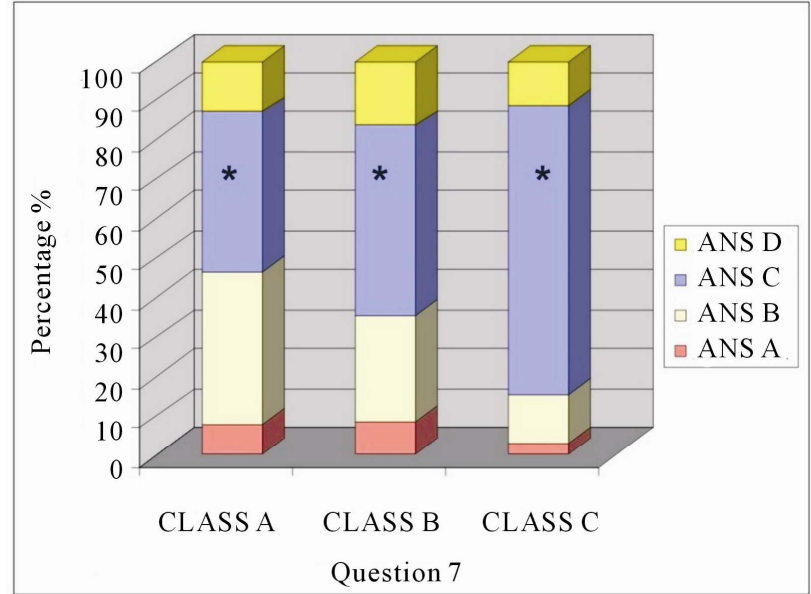

(a)

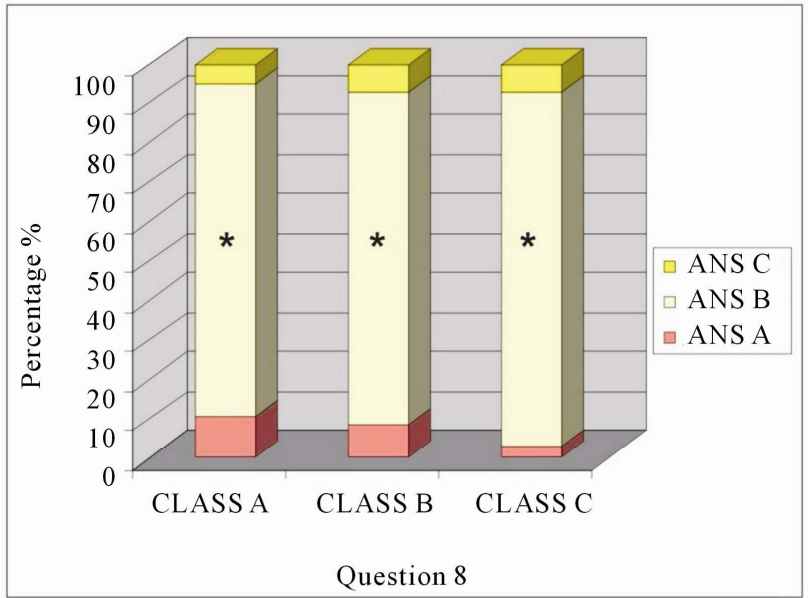

(b)

Figure 4. Percentage distribution of schoolers' responses to questions 7 and 8: (a) Question 7, (b) Question 8. * Denotes the correct option.

vast majority of schoolers in all three classes selected the correct second option with rates of $84.4 \%, 84.9 \%$ and 90.1\% from (A) to (C) class respectively (Figure 4(b)). These data illustrate the particularly important and gratifying fact that they seem to be aware that oil is not a renewable natural resource. The results of our study on this question are in stark contrast with the findings of investtigations in two other countries. The first was held in Turkey and showed limited knowledge and many misconceptions of schoolers on renewable energy issues, despite the fact that at the University of the City where the investigation was carried there is a Research Centre for renewable energy resources [25]. In a similar survey conducted by a group of Finnish researchers in Jordanian high schoolers, a limited ability in the distinction between renewable and non-renewable resources was observed [26].
The ninth question was designed to investigate the schoolers' knowledge on sustainable development. The correct option was annotated at a rate of $44.1 \%, 35.6 \%$ and $61.5 \%$ with respect to (A), (B) and (C) class (Figure 5(a)). These rates, in general, should not be considered satisfactory, as less than half of the (A) and (B) class ones are aware that the concept of sustainable development is synonymous with the protection and not the destruction of the environment. This is discouraging as these rates are for a very general question to which the scientific details of the concept of sustainability that would encounter difficulties to schoolers were not contained. On the contrary, a general knowledge of the concepts of sustainability or sustainable development is imperative, given the fact that we run the United Nations' Decade of Education for Sustainable Development [27].

In the last question, schoolers were asked to report us 


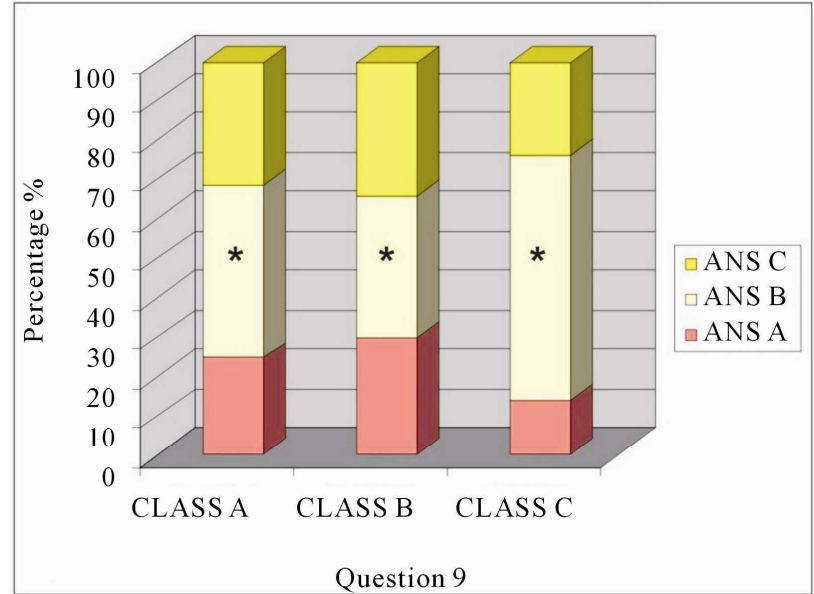

(a)

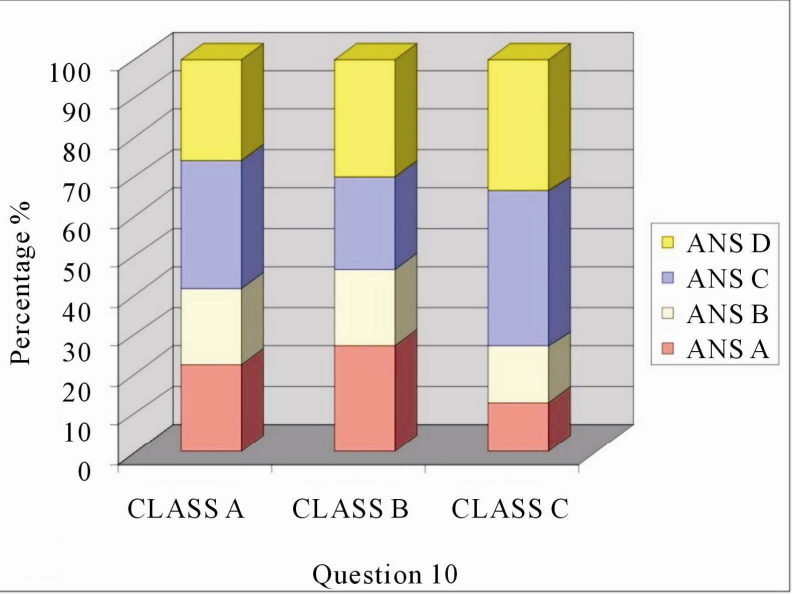

(b)

Figure 5. Percentage distribution of schoolers' response to questions 9 and 10: (a) Question 9, (b) Question 10. *Denotes the correct option.

from which source were informed on the concept of sustainable development. The $32.4 \%$ and the $39.4 \%$ of the (A) and (C) class ones respectively reported the School as the main source for their informing, while the $30.1 \%$ of the (B) class ones responded that they never had any information received on the above referred concept. The first option of this question, namely that the main source of information is the traditional Media (TV, newspaper, radio), was selected by the $22 \%$ of the (A) class, $27.4 \%$ of the (B) class and $12.7 \%$ of the (C) class schoolers. The Internet, although in our time it is very popular to children and teenagers, was selected by the $19.5 \%, 19.2 \%$ and $14.1 \%$ of (A), (B) and class ones respectively (Figure 5(b)). In a survey conducted in Turkey the results were quite similar, named that the main source of information for schoolers was the School (39\%) followed the newspapers (17\%) and the Internet (14\%) [18]. Another survey among Mexican and English schoolers confirmed the above observations, as it recorded the School (29.8\%) and television (29.4\%) as the main sources of information for children about environmental issues [19].

Using the Chi Square test we aimed to consider whether the attributes "Response" and "Age" are independent. For this reason we applied the Chi Square test for each question separately. Table 1 shows the degree of correlation of the one attribute, i.e. the age of children, in relation to characteristic, which is their response. The analysis shows that schoolers response to questions 2, 3, 4, 7 and 9 appeared to be related to their age, while the corresponding relationship to questions $1,5,6,8$ and 10 appeared to be independent. However, taking into account the acquired knowledge from the response we had when we independently interviewed their teachers it appeared that the schoolers should had responded according to their age. Taking into account our overall conversa-
Table 1. Correlation between the age of schoolers and the response to each question.

\begin{tabular}{cccc}
\hline $\begin{array}{c}\text { Question } \\
\text { Number }\end{array}$ & Chi Square & $\begin{array}{c}\text { Degrees of } \\
\text { Freedom }\end{array}$ & p \\
\hline 1 & 6.27 & 6 & 0.05 \\
2 & 14.15 & 6 & 0.05 \\
3 & 17.56 & 4 & 0.05 \\
4 & 17.92 & 6 & 0.05 \\
5 & 4.30 & 4 & 0.05 \\
6 & 4.07 & 4 & 0.05 \\
7 & 20.54 & 6 & 0.05 \\
8 & 3.48 & 4 & 0.05 \\
9 & 11.01 & 4 & 0.05 \\
10 & 8.34 & 6 & 0.05 \\
\hline
\end{tabular}

tions we consider that misconceptions have been developed due to the various types of their socialization.

\section{Conclusions}

In the present study we attempted an overall investigation on the knowledge of high school children on certain environmental issues. This study becomes particularly important, if we consider that these children are approaching graduation from Secondary Education, while for many of them will this is their final stage of the so called "Formal" or "Official" education.

Environmental issues, as it is well known, are too many and it would have been impossible a full record of students' knowledge on these issues. However, in this study we attempted to achieve an overview of their knowledge and misunderstandings in ten of these issues. 
The analysed data present the generated overall picture being moderately satisfactory, since only in questions 1, 6 and 8 the vast majority of pupils responded to the correct option. In the meantime, the responses to the questions 3, 4 and 7 are considered moderately satisfactory, while their knowledge regarding the questions 2, 5 and 9 is appeared to be limited.

The present data indicate that there is a lack of knowledge among schoolers on certain environmental concepts and sustainable development. Thus there is a need to improve the environmental information addressed to the public. Tsekos and Matthopoulos [28] pointed out that journalist's education in environmental issues needed to be improved in order for them to properly transfer that information to public.

Actions, to our opinion, that could contribute to improving the observed schoolers' environmental awareness are: a) alteration of the character of environmental courses from elective ones to compulsory, b) continuous training of high school teachers in environmental sciences by seminars and c) educational institutes in each country to advance the organization of a database with survey data similar to our research and that should seriously be considered in future planning teaching curricula and schoolbooks.

The outcome of the present study in relation to published observations denotes that the Formal Environmental Education in Greece (the way it is instructed within the Formal Educational System) does not meet the requirements of our times.

An official evaluation of the present data supplemented with data from additional urban areas in Greece accompanied by data deriving from rural areas should be used to shape guide-lines to improve the existing situation beginning from the compulsory education.

In this context, one of the co-authors coordinates the Greek Science/Environmental Curriculum reform which is currently in its pilot implementation in 200 schools in national level [29].

\section{REFERENCES}

[1] J. D. Novak and B. D. Gowin, "Learning How to Learn," Cambridge University Press, New York, 1984.

[2] V. John-Steiner, "Notebooks of the Mind; Explorations of Thinking," Harper and Row, New York, 1987.

[3] E. Mavrikaki, "Environmental Education and Constructivism: Theoretical Approaches in a Compatible Relationship,” In: A. Georgopoulos, Ed., Environmental Education: The New Civilization Which Arise, Gutenberg, Athens, 2005, pp. 421-436.

[4] K. Plakitsi, "Didactics of Natural Sciences in Pre-School and Early School Age: Modern Trends and Perspectives," Patakis Publications, Athens, 2008.

[5] G. Claxton, “Teaching to Learn: A Direction for Educa- tion,” Cassell, London, 1990.

[6] D. H. Schunk, P. R. Pintrich and J. L. Meece, "Motivation in Education: Theory, Research and Applications," Pearson/Merrill Prentice Hall, Upper Saddle River, 2008.

[7] D. Ausubel, J. Novak and H. Hanesian, "Education Psychology: A Cognitive View,” Holt, Rinehart and Winston, New York, 1978.

[8] G. J. Posner, G. J. Strike, P. W. Hewson and W. A. Gertzog, "Accommodation of a Scientific Conception: Towards a Theory of Conceptual Change,” Science Education, Vol. 66, No 2, 1982, pp. 211-227. doi:10.1002/sce.3730660207

[9] NAAEE, "Guidelines for the Initial Preparation of Environmental Educators,” NAAEE, Rock Spring, 2000.

[10] D. Spiropoulou, D. Kostopoulos and C. P. Jacovides, "Greek Children's Alternative Conceptions on Weather and Climate,” School Science Review, Vol. 81. No. 29, 1999, pp. 55-59.

[11] A. Dimitriou and V. Christidou, "Pupils Understanding of Air Pollution,” Journal of Biological Education, Vol. 42, No. 1, 2007, pp. 24-29. doi:10.1080/00219266.2007.9656103

[12] C. A. Tsekos, P. Zamparas, D. G. Theocharopoulos and D. P. Matthopoulos, "Mountainous Environments: Greek Primary School Children's Ideas and Misconceptions," Journal of Science Education, Vol. 12, No. 1, 2011, pp. 24-28.

[13] L. Kastani, P. Ragkou and A. Karameris, "Exploring the Holistic Understanding of the Students in the School of Forestry and the Natural Environment at Aristotle University of Thessaloniki Regarding the Complexity of Environmental Issues and the Concept of Sustainable Development," In: K. Koutsopoulos, Ed., Environmental Education for an Integrated Development, National Technical University of Athens and Ministry of Education and Religious Affairs, Athens, 2009, pp. 51-66.

[14] K. Plakitsi, et al., "Activity Theory in Formal and Informal Science Education,” Sense Publishers, Rotterdam, in press.

[15] A. Ifegbasan, "Exploring Secondary School Students Understanding and Practices of Waste Management in Ogun State, Nigeria," International Journal of Environmental and Science Education, Vol. 5, No. 2, 2010, pp. 201-215.

[16] E. Boyes, M. Stanisstret and Z. Yongling, “Combating Global Warming: The Ideas of High School Students in the Growing Economy of South East China,” International Journal of Environmental Studies, Vol. 65, No. 2, 2008, pp. 239-251. doi:10.1080/00207230701284543

[17] B. Daniel, M. Stanisstreet and E. Boyes, "How Can We Best Reduce Global Warming? School Students' Ideas and Misconceptions," International Journal of Environmental Studies, Vol. 61, No. 2, 2004, pp. 211-222. doi:10.1080/0020723032000087907

[18] A. Kilinc, M. Stanisstreet and E. Boyes, “Turkish Students' Ideas about Global Warming," International Journal of Environmental and Science Education, Vol. 3, No. 2, 2008, pp. 89-98.

[19] L. Barraza and A. D. Cuarón, "How Values in Education 
Affect Children's Environmental Knowledge,” Journal of Biological Education, Vol. 39, No. 4, 2004, pp. 18-23. doi:10.1080/00219266.2004.9655949

[20] S. Menzel and S. Bögeholz, "Values, Beliefs and Norms That Foster Chilean and German Pupils' Commitment to Protect Biodiversity," International Journal of Environmental and Science Education, Vol. 5, No. 1, 2010, pp. 31-49.

[21] V. Bar, “Children's Views about Water Cycle,” Science Education, Vol. 73, No. 4, 1978, pp. 481-500. doi:10.1002/sce.3730730409

[22] R. H. Aron, M. A. Francek, B. D. Nelson and W. J. Biasrd, “Atmospheric Misconceptions,” The Science Teacher, Vol. 61, No. 1, 1994, pp. 30-33.

[23] B. K. Tsurusaki and C. W. Anderson, "Students Understanding of Connections between Human Engineered and Natural Environmental Systems," International Journal of Environmental and Science Education, Vol. 5, No. 4, 2010, pp. 407-433.

[24] E. Boyes, M. Stanisstreet and V. Spiliotopoulou-Papantoniou, "The Ideas of Greek High School Students about the 'Ozone Layer'," Science Education, Vol. 83, 1999, pp. 724-737.

[25] H. S. Tortop, “Awareness and Misconceptions of High
School Students about Renewable Energy Resources and Applications: Turkey Case,” Energy Education Science and Technology Part B, Vol. 4, No. 3, 2012, pp. 18291840.

[26] A. Zyadin, A. Puhakka, P. Ahponnen, T. Cronberg and P. Pelkonen, "School Students' Knowledge Perceptions and Attitudes toward Renewable Energy in Jordan,” Renewable Energy, Vol. 45, 2012, pp. 78-85. doi:10.1016/j.renene.2012.02.002

[27] UNESCO, "UN Decade of Education for Sustainable Development 2005-2014: International Implementation Scheme,” UNESCO, Paris, 2005.

[28] C. A. Tsekos and D. P. Matthopoulos, "Environmental News in Greece: Evaluation of the Way Newspapers Deal with Environmental Issues,” International Journal of Environmental Studies, Vol. 65, No. 2, 2008, pp. 215-224. doi:10.1080/00207230701832572

[29] K. Plakitsi, A. Kouloubaritsi, V. Perraki, K. Klonari, A. Spirtou, P. Papadopoulou, M. Kalogiannakis, G. Soulios, N. Kolios, K. Rizaki, E. Stamoulis, T. Zoupidis, A. Mandrikas, A. Melista and G. Tsaparlis, "New Greek Curriculum for Compulsory Education: Science and Environmental Education,” Institute of Educational Policy, Athens, 2011. 